\title{
An Empirical Evaluation of Egg Demand in the United States
}

\author{
Rafael Bakhtavoryan ${ }^{1}\left(\mathbb{D}\right.$, Vardges Hovhannisyan ${ }^{2 *}\left(\mathbb{D}\right.$, Stephen Devadoss ${ }^{3}(\mathbb{D})$ and Jose Lopez ${ }^{1}$ \\ ${ }^{1}$ College of Agricultural Sciences and Natural Resources, Texas A\&M University, Commerce, TX, USA, ${ }^{2}$ Agricultural and \\ Applied Economics, University of Wyoming, Laramie, WY, USA and ${ }^{3}$ Department of Agricultural and Applied \\ Economics, Texas Tech University, Lubbock, TX, USA \\ ${ }^{*}$ Corresponding author. Email: Rafael.Bakhtavoryan@tamuc.edu
}

\begin{abstract}
We adopt an EASI model to estimate demand for omega-3, organic, cage-free, and conventional eggs in the United States. Our empirical framework accounts for demand inter-dependencies among these egg types, while allowing for unrestricted Engel curves, unobserved consumer heterogeneity, and a broader product and geographic coverage. We further address endogeneity of prices and expenditures and left-censoring induced by disaggregate data. Our results indicate that the demand for organic and cage-free eggs is priceelastic, while the demand for omega- 3 and conventional eggs is price-inelastic. Additionally, we establish strong substitutability relationships between the eggs. Finally, we measure consumer welfare consequences of rising domestic egg prices brought by Japan's egg import tariff reductions.
\end{abstract}

Keywords: compensating variation; egg demand structure; Exact Affine Stone Index model; expenditure and price endogeneity

JEL Classification: D12

\section{Introduction}

Recent years have seen consumers develop affinity for vegetarian, organic, omega-3, cage-free, free-range, fertile, nutrient-enhanced, and other specialty eggs, which is believed to be brought by rising health consciousness and healthy lifestyles, increased awareness, and concern about animal welfare (Bakhtavoryan and Lopez, 2020; Grand View Research, 2019; Lusk, 2010). For example, the number of individuals in the United States consuming organic eggs increased by $14 \%$ over the span of 2014-2017, reaching 80.35 million (Statista Research Department, 2020). This market dynamic has gone hand-in-hand with a considerable expansion of production of specialty eggs in the United States, which reflects producer efforts to accommodate changing consumer egg preferences (American Egg Board, 2020; Grand View Research, 2019). As a testament to this recent development, McDonald's, Walmart, Sysco, and many other companies have pledged to fully convert to cage-free eggs by year 2025 in light of intensifying consumer demand for corporate social responsibility (GRO Intelligence, 2019). It is also important to note that global markets have not been immune to these changes in consumer tastes and preferences, as a result of which the global market of omega-3-enriched products was forecasted to grow to $\$ 3.766$ billion over the period 2019-2025, indicating an impressive compound annual growth rate of $7.4 \%$ (Grand View Research, 2019).

Although the overall egg consumption in the United States has been on a steady rise since 2016, conventional eggs have been facing stiff competition from specialty products such as organic,

(c) The Author(s), 2021. Published by Cambridge University Press on behalf of the Southern Agricultural Economics Association. This is an Open Access article, distributed under the terms of the Creative Commons Attribution licence (http://creativecommons.org/licenses/by/4.0/), which permits unrestricted re-use, distribution, and reproduction in any medium, provided the original work is properly cited. 
cage-free, and omega-3 eggs (US Department of Agriculture (USDA, 2020). ${ }^{1}$ Omega-3-enriched eggs contain more omega-3 relative to conventional eggs and are produced by hens whose feed is supplemented with an omega-3 source such as flax seeds. Certified organic eggs are produced by hens that are kept in cage-free conditions and whose feed contain organic grains without pesticides, fertilizer, or animal by-products. Cage-free eggs are produced by hens that are not confined to cages and are free to walk around the hen house, perch on roosts, and lay eggs in nests.

While some consumers may have developed strong preferences for specialty eggs in this relatively short span of time, many others may still be less demanding and discerning when it comes to egg consumption and product differences (Bakhtavoryan and Lopez, 2020; USDA, 2020). Therefore, the extent of perceived substitutability between conventional, organic, cage-free, and omega-3 eggs remains largely unknown, due predominantly to the lack of detailed data on egg consumption by product type. ${ }^{2}$ Limited data have also hampered gaining an accurate estimate of consumer income response for egg products defined at sufficiently disaggregate level.

We analyze demand inter-relationships among various egg types in the United States using a system's framework in line with Huang and Lin (2000), Asselin (2005), Chase et al. (2009), Lusk (2010), Chang, Lusk, and Norwood (2010), Shiratori (2011), Heng (2015), and Bakhtavoryan and Lopez (2020). Meanwhile, our study makes four distinct contributions to the previous literature. First, it exploits recent advances in consumer theory by applying an Exact Affine Stone Index (EASI) model to the estimation of egg demand structure (Lewbel and Pendakur, 2009). In addition to preserving all of the desirable features of the Almost Ideal Demand System (AIDS) of Deaton and Muellbauer (1980) and other workhorse demand models, the EASI framework recognizes unobserved consumer heterogeneity that can be responsible for a significant portion of variation in consumer behavior (Pendakur, 2009). It further allows for flexible Engel curves, rather than imposing a priori restrictions on consumer income response, which is essential from the perspective of credible identification of income effects (Lewbel and Pendakur, 2009). Finally, our empirical framework controls for unobserved regional heterogeneity that may well reflect the effects of local food customs and cultures, which are usually difficult to detect or measure. Second, we address egg price endogeneity caused by the simultaneous determination of egg supply and demand and expenditure endogeneity arising from the simultaneous determination of budget shares and expenditures. Specifically, we employ a Full Information Maximum Likelihood (FIML) estimation procedure in the spirit of Dhar, Chavas, and Gould (2003) and construct Hausman-type instruments using price data from neighboring markets. The FIML framework improves upon the alternative procedures such as the instrumental variable approach in that parameter asymptotic efficiency is independent of the choice of price and expenditure instruments. ${ }^{3}$ Ignoring price and expenditure endogeneity, as has been done in this strain of literature, can induce estimation bias and can generate inconsistent parameter estimates, ultimately leading to inaccurate projections of future egg demand, and erroneous policy implications (e.g., Dhar, Chavas, and Gould, 2003; Hovhannisyan and Bozic, 2017; Hovhannisyan et al., 2020). Third, our empirical analysis offers a broader egg product and geographical coverage in comparison to many previous studies, thus having the promise of generating a fuller characterization of the egg demand structure. ${ }^{4}$ To accomplish this objective, we use Nielsen Homescan household-level data providing sufficiently detailed information on table eggs and covering almost 200 retail markets throughout the United States. We further address an econometric issue of

\footnotetext{
${ }^{1}$ It deserves noting that $23.6 \%$ of the current table egg layer flock is used in organic and cage-free shell eggs production, 17.8\% (about 60 million hens) of which produce non-organic cage-free eggs (United Egg Producers, 2020).

${ }^{2}$ While a number of previous studies examined demand inter-connectedness among egg products, to the best of our knowledge, no single study provides an exhaustive coverage of egg products (see for example, Lusk [2010]).

${ }^{3}$ The FIML is also asymptotically more efficient vis-à-vis 3SLS and GMM procedures in empirical settings where the underlying modeling assumptions hold.

${ }^{4}$ For example, Lusk (2010) omits omega-3 eggs from the empirical analysis of egg demand system, while confining the analysis to two specific geographical markets in the United States.
} 
left-censoring (i.e., non-purchase of certain eggs by specific households) stemming from the degree of our data disaggregation via a two-step procedure (Shonkwiler and Yen, 1999). Fourth, we demonstrate the policy relevance of our findings by evaluating the consumer welfare consequences of rising egg prices in the United States induced by Japan's tariff reductions on egg imports. Our choice of Japan for this analysis reflects the fact that Japan remains one of the largest markets for US egg exports (American Egg Board, 2020; USDA ERS, 2020). Specifically, in 2019, the US total egg exports to Japan amounted to 26.2 million dozen or $\$ 38.248$ million, making it the fourth largest US egg export destination after Canada, Mexico, and Hong Kong (USDA ERS, 2020; USDA FAS, 2020).

Our results provide important insights into household preferences for the various table eggs. Specifically, we find that demand for organic and cage-free eggs is price-elastic suggesting greater availability of substitutes thereof, while that for omega-3 and conventional eggs is price-inelastic. This information can assist egg manufactures in their input procurement and inventory management decisions. Based on income elasticity estimates, we further find that the table eggs considered are normal goods; moreover, they are necessities. We also empirically establish the importance of a certain set of household demographic characteristics as egg demand drivers, which can help egg manufacturers design effective marketing strategies to better serve the needs of different demographic markets. Finally, our estimated welfare effects of Japan's egg import tariff reductions point to relatively small welfare losses on a national scale, the total impact of which may be bigger in all likelihood, once all the consumer goods containing eggs are considered.

The remainder of this paper is structured as follows. Section 2 provides the methodology and econometric procedures performed in the current study. Section 3 presents a brief description of the Nielsen Homescan data underlying the empirical analysis. Section 4 discusses the empirical estimation and identification strategies and presents the results emerging from this study. Concluding remarks are presented in Section 5.

\section{Methodology}

In this section, we briefly introduce the EASI demand specification utilized in our empirical analysis. Next, we discuss data censoring issues resulting from our use of disaggregate household expenditure survey data and explain the procedure used to address this econometric issue. This is followed by a succinct description of the sources of price and expenditure endogeneity, and our identification strategy. Finally, we present an analytical framework for evaluating consumer welfare consequences of the reduced trade barriers.

\subsection{The Exact Affine Stone Index Demand Specification}

The Exact Affine Stone Index (EASI) system is a theory-based demand model developed by Lewbel and Pendakur (2009). Let $w_{\text {hit }}$ denote the household $h$ 's budget share of product $i$ in period $t$; $p_{h j t}$ be price paid by household $h$ for product $j$ in period $t$; $y_{h t}$ represent household real expenditures on the set of products in question in period $t ; u_{h i t}$ reflect unobserved preference heterogeneity; $N, H$, and $R$ denote the number of products, households, and regions, respectively; $L$ be the highest order of income polynomial; and $\alpha_{i j}, \beta_{i l} \eta_{i r}, \varphi_{i t}$, and $\gamma_{i m}$ parameters representing the price, income, region, time, and demographic effects, respectively. The EASI specification can then be represented by the following system of demand equations:

$$
\begin{array}{r}
w_{h i t}=\alpha_{i 0}+\sum_{r=1}^{R-1} \eta_{i r} \mathrm{~K}_{r}+\sum_{t=1}^{T-1} \varphi_{i t} \Upsilon_{t}+\sum_{m=1}^{M} \gamma_{i m} D_{m h t}+\sum_{j=1}^{N} \alpha_{i j} \log \left(p_{h j t}\right)+\sum_{l=1}^{L} \beta_{i l} y_{h t}^{l}+u_{h i t}, \\
\forall h=1, \ldots, H ; i=1, \ldots, N ; t=1, \ldots, T ; r=1, \ldots, R,
\end{array}
$$

where $D_{m h t}$ represents demographic characteristic $m$ of household $h$ in period $t$ and $K_{r}$ and $\Upsilon_{t}$ are region and time fixed effects, respectively, that are incorporated into the EASI budget 
share equations via the demographic translation procedure (Pollak and Wales, 1981). The specific economic and demographic characteristics include household income, size, age, presence of children in the household aged below 18, household head's age, employment status, education level, marital status, race, and ethnicity. Our goal with the inclusion of regional fixed effects is to control for the unobserved regional heterogeneity such as local food customs, cultures, and traditions that may have strong influence on consumer food preferences and are relatively stable over time (e.g., Guta, 2012; Miller and Alberini, 2016). Finally, it is important to note that the demand system in (1) is subject to the theoretical restrictions of adding-up $\sum_{i=1}^{N} \alpha_{i 0}=1 ; \sum_{i=1}^{N} \eta_{i r}=0$; $\sum_{i=1}^{N} \varphi_{i t}=0 ; \quad \sum_{i=1}^{N} \gamma_{i m}=0 ; \quad \sum_{i=1}^{N} \beta_{i l}=0, \forall l=1, \ldots, L ; \sum_{i=1}^{N} \alpha_{i j}=0(\forall k=1, \ldots, N)$ and symmetry $\alpha_{i j}=\alpha_{j i}(\forall i, j=1, \ldots, N)$. Homogeneity is satisfied when $\sum_{j=1}^{N} \alpha_{i j}=0$ for $j=1,2, \ldots, N$.

As will be discussed below, the endogeneity and data censoring econometric issues present estimation challenges that require proper addressing. To make these procedures more tractable, therefore, we adopt a linear approximate EASI (LA-EASI) model derived by Lewbel and Pendakur (2009), wherein $y_{h t}$ is represented as Stone price-deflated real expenditures: ${ }^{5}$

$$
y_{h t}=\log \left(X_{h t}\right)-\sum_{j=1}^{N} w_{h j t} \log \left(p_{h j t}\right),
$$

where $X_{h t}$ denotes household $h$ 's nominal expenditures on the products considered in period $t$.

\subsection{A Censored LA-EASI Demand Model}

Studies using household-level data are plagued with a data censoring issue, where a considerable number of households report zero consumption of certain products. Unless properly accounted for, this can lead to imprecise estimated effects of demand determinants, inaccurate elasticity estimates, and erroneous policy advice (Heckman, 1976). Our use of the disaggregate household-level Nielsen Homescan data also entails left-censoring and, thus, requires proper addressing of this econometric issue. Specifically, we employ a two-step procedure proposed by Shonkwiler and Yen (1999). In the first step, we estimate households' product $i$ purchase probability $\Phi\left(Z_{i} \theta\right)$ (i.e., univariate standard normal cumulative distribution) and $\phi\left(Z_{i} \theta\right)$ (i.e., probability density function), where $Z_{i}$ represents a vector of household demographic and other characteristics, and $\theta$ is a parameter vector. ${ }^{6}$ In the second step, we adjust the EASI demand equations to account for the purchase probabilities. Error term $\left(\xi_{\text {hit }}\right)$ reflects the unobserved budget share determinants.

$$
\begin{aligned}
w_{h i t}= & \\
& \Phi\left(Z_{i} \theta\right)\left(\alpha_{i 0}+\sum_{r=1}^{R-1} \eta_{i r} \mathrm{~K}_{r}+\sum_{t=1}^{T-1} \varphi_{i t} \Upsilon_{t}+\sum_{m=1}^{M} \gamma_{i m} D_{m h t}+\sum_{j=1}^{N} \alpha_{i j} \log \left(p_{h j t}\right)+\sum_{l=1}^{L} \beta_{i l} y_{h t}^{l}\right) \\
& +\delta_{i} \phi\left(Z_{i} \theta\right)+\xi_{h i t} \\
& \forall h=1, \ldots, H ; \quad t=1, \ldots, T ; r=1, \ldots, R
\end{aligned}
$$

Given that both purchasing and non-purchasing households are included in the second-step analysis, we replace the missing prices for the latter households with choke prices (e.g., Arnade et al., 2005). These represent prices that exceed non-consuming households' reservation price,

\footnotetext{
${ }^{5}$ Unlike the AIDS and similar models, $y_{h t}$ is the affine transformation of the Stone price-deflated real expenditures, where, by the very design, the Stone price index is the correct deflator of food expenditures (Pendakur, 2009).

${ }^{6}$ Specifically, we include regional and time fixed effects, household income, size, presence of children, as well as household head's race, age, employment, education, and marital status.
} 
thus preventing them from buying the products in question. Specifically, we compute choke prices as the highest price observed in each market raised by $5 \%{ }^{7}$

We evaluate the EASI-based compensated (Hicksian) price elasticities $\left(e_{i j}^{H}\right)$ using the following formula (e.g., Zhen et al., 2013):

$$
e_{i j}^{H}=\frac{\gamma_{i j} \Phi\left(Z_{i} \theta\right)}{w_{i}}+w_{j}-\delta_{i j}, \forall i, j=1, \ldots, N,
$$

where $\delta_{i j}$ is the Kronecker delta that equals 1 when $i=j$, and 0 otherwise.

Further, we calculate the EASI expenditure elasticities using the following equation:

$$
E=(\operatorname{diag}(W))^{-1}\left[\left[\left(I_{N}+B P^{\prime}\right)^{-1} B\right] \Phi\left(Z^{\prime} \theta\right)\right]+1_{N},
$$

where $E$ is the $(N \times 1)$ vector of expenditure elasticities; $W$ is an $(N \times 1)$ vector of observed product budget shares; $I_{N}$ is an $(N \times j)$ identity matrix; $B$ is a $(N \times 1)$ vector with its $i^{\text {th }}$ element given by $\sum_{l=1}^{L} \beta_{i l} l y^{l-1} ; P$ is an $(N \times 1)$ vector of log-transformed prices; $\Phi\left(Z^{\prime} \theta\right)$ is an $(N \times 1)$ vector; and $1_{N}$ is an $(N \times 1)$ unity vector (see Appendix B for a $2 \times 2$ system).

Finally, the uncompensated (Marshallian) prices elasticities $\left(e_{i j}^{M}\right)$ are recovered from the Slutsky equation, where use is made of the compensated price elasticity $\left(e_{i j}^{H}\right)$ and expenditure elasticities $\left(e_{i}\right)$ :

$$
e_{i j}^{M}=e_{i j}^{H}-e_{i} w_{j}
$$

\subsection{Expenditure and Price Endogeneity and Identification Strategy}

Expenditure endogeneity arises due to it appearing on both sides of the EASI demand equations (i.e., $y_{h t}=\log \left(X_{h t}\right)-\sum_{j} w_{h j t} \log \left(p_{h j t}\right)$ and $\left.w_{h i t}=p_{i t} q_{i t} / X_{h t}\right)$ (Dhar, Chavas, and Gould, 2003; Hovhannisyan et al., 2019). Similarly, price endogeneity arises because of the simultaneous determination of supply and demand (Deaton, 1988; Dong, Shonkwiler, and Capps, 1998; Green and Alston, 1990; Zhen et al., 2013). As has been documented in the previous literature, ignoring price endogeneity can result in significant biases and inconsistencies in estimated price and income effects (Hovhannisyan and Shanoyan, 2020; Zhen et al., 2013).

We address both expenditure and price endogeneity by employing a FIML procedure that supplements the EASI demand system with reduced-form expenditure and price equations (Dhar, Chavas, and Gould, 2003; Hovhannisyan and Devadoss, 2020). Specifically, we utilize the following reduced-form expenditure equation that relates expenditures to the respective exogenous shifters:

$$
X_{h t}=\mu_{0}+\sum_{r=1}^{R} \eta_{r} K_{r}+\sum_{t=1}^{T} \varphi_{t} \Upsilon_{t}+\psi_{h t} \bar{X}_{h t}+v_{h t},
$$

where $\bar{X}_{h t}$ is the household income used as an instrument for real expenditures (i.e.); $v_{h t}$ reflects unobserved expenditure determinants; and $\mu_{0}, \eta_{r}, \varphi_{t}, \psi_{h t}$ are parameters:

It is important to point out that based on equations (3) and (7), we obtain the income elasticity of demand as $\frac{\partial \ln q_{i}}{\partial \ln X} \frac{\partial \ln X}{\partial \ln \bar{X}}$, where $\frac{\partial \ln X}{\partial \ln \bar{X}}$ is the income elasticity of expenditures and $\frac{\partial \ln q_{i}}{\partial \ln X}$ is the expenditure elasticity of demand.

In turn, the reduced-form price equations relate actual egg prices $\left(p_{h j t}\right)$ to the respective instruments $\left(\stackrel{\rho}{h j t}_{h t}\right)$ as illustrated below:

$$
p_{h j t}=\delta_{0}+\sum_{r=1}^{R} \pi_{r} K_{r}+\sum_{t=1}^{T} \rho_{t} \Upsilon_{t}+\omega \tilde{p}_{h j t}+\varsigma_{h j t},
$$

\footnotetext{
${ }^{7} \mathrm{We}$ thank an anonymous referee for this suggestion.
} 
where $\stackrel{\rho}{h j t}_{h t}$ represents the price instrument for product $j ; \varsigma_{h j t}$ denotes unobserved price determinants; and $\delta_{0}, \pi_{r}, \rho_{t}, \omega$ are parameters.

To address price endogeneity, we utilize Hausman-type instruments constructed from prices in neighboring markets (Hausman et al., 1994). Identification in this setting relies on the assumption that prices from these adjacent markets reflect supply shocks only. Nevertheless, we acknowledge that this approach is of limited empirical value when, for example, nation-wide advertising campaigns induce positive demand shocks across various markets. ${ }^{8}$ Finally, we adopt a Durbin-WuHausman (DWH) test procedure to empirically evaluate the expenditure and price endogeneity (see Dhar, Chavas, and Gould (2003) for more details on this test procedure). The null hypothesis maintains an assumption of expenditure and price exogeneity, and the test statistic has a $\chi^{2}(g)$ distribution with $g$ being the number of potentially endogenous variables.

\subsection{Consumer Welfare Analysis of Japanese Tariff Reduction}

The United States and Japan reached a trade agreement in October 2019, which envisaged an improved market access for a number of agricultural and industrial products through a series of tariff reductions by both countries (Executive Office of the President of the United States, 2019).

The tariffs will be phased out in stages with the first stage initiated in January 2020, and the following stages implemented on April 1 of each of the subsequent year (USA Poultry and Egg Export Council (UPEEC, 2019)). For a wide range of agricultural and food products such as certain tree nuts, berries, vegetables, and egg products, tariffs will be eliminated altogether up to an estimated $\$ 3.0$ billion matching access conditions (United States Trade Representative, 2020).

The tariff elimination on egg products by Japan will expand Japanese import demand for US eggs, which will increase egg prices in the United States. While this creates excellent growth opportunities for the US egg industry to export more to Japan, rising egg prices in the United States will be part of the inevitable consequences of these market dynamics soon after this trade liberalization is implemented. Higher egg prices can have adverse welfare effects on the US consumers, given that shell egg sales alone amounted to $\$ 5.8$ billion in 2018 and were projected to grow to $\$ 6.5$ billion by 2022 (The American Egg Board, 2020).

We analyze the consumer welfare changes arising from this tariff reduction using the Hicksian compensating variation (CV) approach, which provides an estimate of income required to compensate for the effects of changing prices under constant utility. Let $E(p, u)$ represent the minimum expenditure needed for obtaining utility level $u$ at a given price vector $p$, and $p_{0}, u_{0}$, and $p_{1}$ denote initial prices, utility, and new prices, respectively. The CV can then be assessed based on (Hausman, 1981):

$$
C V=E\left(p_{1}, u_{0}\right)-E\left(p_{0}, u_{0}\right)=p_{1} q^{h}\left(p_{1}, u_{0}\right)-p_{0} q_{0}\left(p_{0}, u_{0}\right)
$$

where $q_{0}$ is an initial consumption level, $q^{h}\left(p_{1}, u_{0}\right)$ denotes the compensated demand, evaluated at $p_{1}$ and initial fixed utility level of $u_{0}$ (approximated by $q_{0}$ ). Equation (9) is operationalized through the following vector of compensated quantity changes:

$$
d q^{h}=q^{h}\left(p_{1}, u_{0}\right)-q_{0}\left(p_{0}, u_{0}\right)
$$

which yields the following empirically tractable version of the $\mathrm{CV}$ :

$$
C V=p_{1} d q^{h}+d p q_{0}\left(p_{0}, u_{0}\right)
$$

\footnotetext{
${ }^{8} \mathrm{We}$ recognize that price instruments providing explicit reflection of the supply side of the price determination mechanism would be ideal for our purposes. In practice, however, the lack of data on cost shifters presents significant challenges from the perspective of identification of price effects (e.g., Zhen et al., 2013).
} 
where the vector of price changes $d p=p_{1}-p_{0}$ and $d q^{h}$ is calculated as follows:

$$
\frac{d q^{h}}{q}=\sum e^{H}\left(\frac{d p}{p}\right),
$$

where $e^{H}$ is the compensated elasticity matrix.

An important premise underlying the evaluation of egg import tariff reduction by Japan is that the increase in import demand by Japan will cause US egg prices to rise and reduce US consumer welfare. To recover these tariff-induced price changes in the United States, we exploit the following equation ${ }^{9}$ that makes use of the uncompensated own-price elasticities estimated in the current study, and those reported in previous studies, as well as the UPEEC-computed tariff reductions for the US egg products (see for example Devadoss and Sabala, 2020):

$$
\frac{d P}{P}=\frac{e_{M}}{\left[e_{S} \frac{S}{M}-e_{D} \frac{D}{M}-e_{M}\right]} \frac{d \tau}{\tau},
$$

where $P, S, D$ denote egg price, domestic supply, and demand, respectively, $M$ is the Japanese demand for US-produced eggs, $e_{S}, e_{D}, e_{M}$ are elasticities of supply, domestic demand, and import demand for US eggs, respectively, and $\tau=1+t$ with $t$ representing Japanese tariff rate. ${ }^{10}$

\section{Data Description}

We base our empirical analysis on the Nielsen Homescan household-level data comprising almost 200 retail markets and spanning a period of January 2014 to December $2016 .{ }^{11}$ Nielsen Homescan panels represent the largest household scanner data survey systems nation-wide, which compile information on daily retail food purchases by households for at-home use from a variety of stores (i.e., grocery stores, department stores, convenience stores, club stores, etc.). The data contain detailed information on product description, characteristics, quantity purchased, expenditure, and promotion along with household economic and demographic characteristics (age, education level, employment status, and marital status of household heads, household size, presence of children in the household, household income, etc.). ${ }^{12}$ To gauge the representativeness of the Nielsen Homescan panels, we contrast them to those underlying the American Community Survey (ACS). The ACS is the largest annual survey conducted by the US Census Bureau with a sample of 3.5 million households (US Census Bureau, 2019). This comparison revealed important distinctions between the two samples. For instance, the Nielsen-based median household income is $\$ 58,460$, while that from the ACS is $\$ 54,231$. Further, households with at least one child comprise $28 \%$ of the Nielsen data, while the same demographic group accounts for $30 \%$ of the ACS sample. Similar discrepancies are observed across the majority of the remaining demographic variables such as employment status, level of educational attainment, marital status, race, ethnicity, etc. According to Einav, Leibtag, and Nevo (2008), these discrepancies, errors, and their distributions are a common feature of self-reported data such as the Nielsen Homescan, which is due in no small part to recording mistakes. Therefore, the empirical results from this study should be interpreted with these discrepancies in mind.

\footnotetext{
${ }^{9}$ We fully understand that this trade liberalization will benefit US egg producers, which will be more than consumer welfare loss. Since our focus is on demand analysis, we present only the welfare loss of US egg consumers.

${ }^{10}$ Details concerning the derivation of equation (14) are presented in the Appendix.

${ }^{11}$ The conclusions drawn from the Nielsen data are those of the researcher(s) and do not reflect the views of Nielsen. Nielsen is not responsible for, had no role in, and was not involved in analyzing and preparing the results reported herein.

${ }^{12}$ We acknowledge that the Nielsen Homescan panels are not representative of the US population at large. Specifically, these tend to be consumers that choose to scan their data after shopping, tend to be biased toward habit formation, and probably exhibit other biases."
} 
Table 1. Descriptive statistics of the variables used in the analysis

\begin{tabular}{|c|c|c|c|c|c|}
\hline Variable & Mean & SD & Variable & Mean & SD \\
\hline Quantity of omega-3 (count) & 10.91 & 36.49 & Age: $45-64$ years & 0.50 & 0.50 \\
\hline Quantity of organic (count) & 4.44 & 33.50 & Age: 65 years and above* & 0.20 & 0.40 \\
\hline Quantity of cage-free (count) & 4.74 & 27.28 & Employment: under 35 hours & 0.18 & 0.39 \\
\hline Quantity of conventional (count) & 159.06 & 186.85 & Employment: 35 hours and above & 0.39 & 0.49 \\
\hline Price of omega-3 (\$/egg) & 0.26 & 0.04 & Employment: unemployed ${ }^{*}$ & 0.42 & 0.49 \\
\hline Price of organic (\$/egg) & 0.35 & 0.04 & Education: less than high school & 0.02 & 0.14 \\
\hline Price of cage-free (\$/egg) & 0.26 & 0.03 & Education: high school only & 0.24 & 0.42 \\
\hline Price of conventional (\$/egg) & 0.16 & 0.06 & Education: some college degree only & 0.31 & 0.46 \\
\hline Budget share of omega-3 & 0.09 & 0.23 & Education: at least college degree ${ }^{\star}$ & 0.44 & 0.50 \\
\hline Budget share of organic & 0.03 & 0.14 & Marital status: married & 0.66 & 0.47 \\
\hline Budget share of cage-free & 0.03 & 0.13 & Marital status: widowed & 0.06 & 0.25 \\
\hline Budget share of conventional & 0.84 & 0.30 & Marital status: divorced or separated & 0.14 & 0.35 \\
\hline Median household income $(\$ 1,000)$ & 58.46 & 29.14 & Marital status: single* & 0.13 & 0.34 \\
\hline Household size: one member & 0.22 & 0.41 & Race: White & 0.81 & 0.39 \\
\hline Household size: two members & 0.40 & 0.49 & Race: Black & 0.11 & 0.31 \\
\hline Household size: three members & 0.16 & 0.36 & Race: Asian & 0.03 & 0.18 \\
\hline Household size: four members & 0.13 & 0.34 & Race: Other ${ }^{\star}$ & 0.05 & 0.22 \\
\hline Household size: five members and more* & 0.09 & 0.29 & Ethnicity: Hispanic & 0.07 & 0.25 \\
\hline $\begin{array}{l}\text { Age and presence of children: at least } \\
\text { one child }\end{array}$ & 0.28 & 0.45 & Ethnicity: non-Hispanic* & 0.93 & 0.25 \\
\hline Age and presence of children: none ${ }^{*}$ & 0.72 & 0.45 & Region: East & 0.38 & 0.49 \\
\hline Age: under 25 years & 0.01 & 0.09 & Region: Central & 0.43 & 0.49 \\
\hline Age: $25-44$ years & 0.28 & 0.45 & Region: West* & 0.19 & 0.40 \\
\hline
\end{tabular}

Notes: Asterisk indicates the base category. Researcher(s) own analyses calculated (or derived) based in part on data from The Nielsen Company (US), LLC and marketing databases provided through the Nielsen Datasets at the Kilts Center for Marketing Data Center at The University of Chicago Booth School of Business.

In the spirit of Lusk (2010), we classify egg products into the following four categories: $(i)$ omega-3-enriched eggs; (ii) certified organic eggs (henceforth organic eggs); (iii) cage-free eggs; and (iv) conventional eggs. Table 1 reports the descriptive statistics for the variables underlying our empirical analysis with the total number of observations (i.e., households) of 159,046. It can be observed that conventional eggs are the most popular product (159 eggs/year/per person), which is followed by omega-3-enriched eggs (11 eggs/year/per person), cage-free eggs (5 eggs/year/per person), and organic eggs (4 eggs/year/per person). Budget share statistics mimic that of the amount purchased with conventional eggs accounting for $84 \%$ of total egg expenditures, while the other three egg categories collectively account for the remaining $16 \%$. Based on the unit values calculated as a ratio of total expenditures to the quantity purchased of the respective eggs, organic eggs (\$0.35/egg) are the highest-priced option, while omega-3 and cage-free (both \$0.26/egg), and conventional eggs (\$0.16/egg) are relatively less expensive.

We supplement the household expenditure survey data with household economic and demographic descriptors such as household income, size, region of residence, presence of children in the 
household, household head's age, employment status, education attainment, marital status, race, and ethnicity. The household income variable is operationalized through the median point for the respective income brackets, which generates an average median household income of $\$ 58,460$. It deserves noting that all household demographic characteristics are accounted for by means of binary variables. For example, the household size is broken down into five categories ranging from one member to five members and more households ( $40 \%$ of the sample have two members). At the same time, age and presence of children in the household characteristic reflect two groups comprising households with at least one child below 18 years of age and no children below 18 (72\% of our sample reportedly have no children below 18 ).

Similarly, household head age distribution is accounted for by a set of binary variables representing age under $25,25-44,45-64$, and 65 years of age and above (50\% of the household heads fall in the age group of 45-64). The employment status of the household heads is classified into three categories: employed under 35 hours/week, employed above 35 hours/week, and unemployed. As far as the employment status, $42 \%$ of the sample households have unemployed heads. Educational attainment of household heads is classified into four categories: less than high school, high school only, some college, and at least a college degree ( $44 \%$ of the household heads have at least a college degree).

The marital status of the household heads is classified into four categories: married, widowed, divorced or separated, and single. Households with married heads represent $66 \%$ of the sample households. The effects of the race of household head on egg consumption are accounted for with the use of four categories, namely, White, Black, Asian, and other ( $81 \%$ of the sample households are White). The ethnicity characteristic comprises two categories: Hispanic and non-Hispanic (93\% of the sample households are non-Hispanic). The region characteristic indicates the geographical location of residence of the households. These regions include New England, Middle Atlantic, East North Central, West North Central, South Atlantic, East South Central, West South Central, Mountain, and Pacific. According to the regional profile of the households, $43 \%$ of the sampled households report residing in the central regions of the United States.

It deserves noting that of the total 159,046 households in our sample over 2014-2016, only 27,837 participated in all three years as some households were replaced with new participants. Despite this dynamic, the sample characteristics remained largely stable, with the exception of certain descriptors. Specifically, the share of households with at least one child increased steadily from $22.7 \%$ in 2014 to $24.5 \%$ in 2016 . Meanwhile, the share of households with heads aged $45-64$ decreased from $55.0 \%$ in 2014 to $50.3 \%$ in 2016 , and that for heads within the $25-44$ age group increased from $20.1 \%$ to $24.5 \%$. Finally, the share of employed heads working upwards of 35 hours a week increased from $36.4 \%$ to $39.2 \%$ over $2014-2016$.

\section{Empirical Results}

We estimate a full system of the EASI demand (equation [3]) and reduced-form expenditure and price equations (equations [7]-[8]) via the Full Information Maximum Likelihood (FIML) method using the GAUSSX programming module of the GAUSS software system. The FIML procedure not only allows for contemporaneous correlation across the unobserved egg supply and demand determinants but also accounts for the true simultaneity between the supply and demand factors of price determination mechanism. A major advantage of the FIML approach is that the asymptotic efficiency is independent of the choice of instruments (Dhar, Chavas, and Gould, 2003). The budget share equation for the conventional eggs is omitted from the estimation to avoid the singularity of the variance-covariance matrix of error terms resulting from the adding-up restriction. The parameters associated with the omitted equation are recovered from the theoretical restrictions of adding-up, homogeneity and symmetry. 
Table 2. Summary of the model diagnostic tests

\begin{tabular}{|c|c|c|c|}
\hline Main hypotheses & $\begin{array}{l}\text { Likelihood } \\
\text { Ratio value }\end{array}$ & df. & $P$-value \\
\hline \multicolumn{4}{|l|}{ Model specification tests } \\
\hline (i) Linear vs. Quadratic Engel curves (i.e., $\beta_{i 2}=0, \forall i=1, \ldots, N$ ) & 274.3 & 4 & 0.00 \\
\hline (ii) Quadratic vs. Cubic Engel curves (i.e., $\beta_{i 3}=0, \forall i=1, \ldots, N$ ) & 294.8 & 4 & 0.00 \\
\hline Egg prices and expenditures are exogenous (DWH test) & $2,257.4$ & 55 & 0.00 \\
\hline $\begin{array}{l}\text { Time fixed effects have no significant impacts on egg demand } \\
\left(\eta_{i r}=0, \forall i=1, \ldots, \text { Nor FE vs. no FE) }\right.\end{array}$ & $16,215.9$ & 6 & 0.00 \\
\hline $\begin{array}{l}\text { Unobserved regional heterogeneity has no significant impacts on } \\
\text { egg demand }\left(\eta_{i r}=0, \forall i=1, \ldots, N \text { or FE vs. no FE) }\right.\end{array}$ & $22,043.3$ & 176 & 0.00 \\
\hline
\end{tabular}

Note: Researcher(s) own analyses calculated (or derived) based in part on data from The Nielsen Company (US), LLC and marketing databases provided through the Nielsen Datasets at the Kilts Center for Marketing Data Center at The University of Chicago Booth School of Business.

To empirically ascertain the appropriate structure of Engel curves, we start with a linear function and sequentially increase the order of polynomial (Table 2). Based on a likelihood ratio (LR) test results, a third-degree polynomial is found to provide the best fit of the data. Our endogeneity test results indicate that we may reject the null hypothesis of price and expenditure exogeneity (the estimated DWH $\chi^{2}$ statistic equals 2,257.4 with the associated $P$-value $=0.00$ ), which implies that ignoring endogeneity of demand determinants can lead to biased and inaccurate economic effects. Last, we may reject the null that unobserved regional heterogeneity and time fixed effects do not contribute to the explanatory power of the model (Table 2).

The estimated results of the EASI system are reported in Table 3, while those from the reducedform expenditure and price equations are reported in Table 4 . The vast majority of the parameter estimates are statistically significant at the $1 \%$ significance level. In particular, we find that smaller households tend to allocate higher shares of their egg expenditures to omega- 3 and cage-free eggs, while larger households spend more on organic and conventional eggs. In addition, households with at least one child below 18 allocate higher expenditure shares to omega-3-enriched and organic eggs, and lower expenditure shares to conventional eggs, relative to households with no children. These results indicate that households with children are more conscious in providing perceivably healthful food to their children.

We also find that households with relatively younger heads (i.e., less than 65) spend more on organic, cage-free, and conventional eggs, while omega-3-enriched eggs are more popular with households headed by individuals aged 65 and above. This is consistent with results of Molfino et al. (2014) who find that elderly consumers obtain health benefit from consumption of omega-3-enriched eggs. Compared to households with heads aged 65 and above, households with heads in the 45-64 age group tend to buy more conventional eggs, while households with heads aged 25-44 years spend less on conventional eggs. This may well be reflective of the emerging health trends among millennial consumer group. Further, households with employed heads generally tend to spend more on organic and cage-free eggs compared to the ones with unemployed heads.

Households with heads having less than high school, high school, and some college degree purchase less specialty eggs and more conventional eggs, compared to households with at least college-educated heads. Thus, education plays an important role in consumer specialty egg purchase decisions. In addition, marital status is found to be an important demand determinant, with households with married heads favoring more specialty eggs relative to other egg types.

Race is also found to have significant impacts on egg consumption patterns. Specifically, white households allocate more to conventional eggs at the expense of specialty eggs. Similarly, Black households spend more on conventional eggs and less on omega-3, organic, and 
Table 3. Parameter estimates and standard errors from the EASI model

\begin{tabular}{|c|c|c|c|c|}
\hline Parameters & Omega-3 & Organic & Cage-free & Conventional \\
\hline \multirow{2}{*}{ Intercept $\left(\alpha_{i 0}\right)$} & $-0.3324^{\star \star *}$ & $-0.1706^{\star \star *}$ & $-0.1971^{\star \star \star}$ & $1.7002^{\star \star \star}$ \\
\hline & $(0.0043)$ & $(0.0032)$ & $(0.0033)$ & $(0.0062)$ \\
\hline \multirow[t]{2}{*}{ Price $\left(\alpha_{1 i}\right)$ omega-3 } & $-0.0063^{\star \star \star}$ & 0.0004 & -0.0003 & $0.0062^{\star \star \star}$ \\
\hline & $(0.0004)$ & $(0.0003)$ & $(0.0003)$ & $(0.0005)$ \\
\hline \multirow[t]{2}{*}{ Price $\left(\alpha_{2 i}\right)$ organic } & & $-0.0154^{\star \star \star}$ & $0.0043^{\star \star \star}$ & $0.0108^{\star \star \star}$ \\
\hline & & $(0.0003)$ & $(0.0002)$ & $(0.0003)$ \\
\hline \multirow[t]{2}{*}{ Price $\left(\alpha_{3 i}\right)$ cage-free } & & & $-0.0109^{\star \star \star}$ & $0.0069^{\star \star \star}$ \\
\hline & & & $(0.0003)$ & $(0.0003)$ \\
\hline \multirow[t]{2}{*}{ Price $\left(\alpha_{4 i}\right)$ conventional } & & & & $-0.0239^{\star \star \star}$ \\
\hline & & & & $(0.0006)$ \\
\hline \multirow[t]{2}{*}{ Real expenditure $\left(\beta_{i 1}\right)$} & $0.0028^{\star \star \star}$ & $0.0033^{\star \star \star}$ & $0.0029^{\star \star \star}$ & $-0.0089^{\star \star \star}$ \\
\hline & $(0.0005)$ & (0.0003) & $(0.0004)$ & $(0.0007)$ \\
\hline \multirow[t]{2}{*}{ Real expenditure $\left(\beta_{i 2}\right)$} & $-0.0009^{\star \star \star}$ & $0.0036^{\star \star \star}$ & $0.0007^{\star \star \star}$ & $-0.0034^{\star \star \star}$ \\
\hline & $(0.0002)$ & $(0.0001)$ & $(0.0001)$ & $(0.0003)$ \\
\hline \multirow[t]{2}{*}{ Real expenditure $\left(\beta_{i 3}\right)$} & $-0.0001^{\star *}$ & $0.0008^{* * *}$ & -0.0001 & $-0.0006^{\star \star *}$ \\
\hline & $(0.0000)$ & $(0.0000)$ & $(0.0001)$ & $(0.0001)$ \\
\hline \multicolumn{5}{|l|}{ Region fixed effects } \\
\hline \multirow[t]{2}{*}{ New England } & $0.1733^{\star \star \star}$ & $-0.0158^{\star \star \star}$ & $-0.0262^{\star \star \star}$ & $-0.1312^{\star \star \star}$ \\
\hline & $(0.0027)$ & $(0.0015)$ & $(0.0014)$ & $(0.0019)$ \\
\hline \multirow[t]{2}{*}{ Middle Atlantic } & $0.2050^{\star \star \star}$ & $-0.0212^{\star \star \star}$ & $-0.0343^{\star \star \star}$ & $-0.1495^{\star \star \star}$ \\
\hline & $(0.0023)$ & $(0.0012)$ & $(0.0012)$ & $(0.0016)$ \\
\hline \multirow[t]{2}{*}{ East North Central } & $-0.0082^{\star \star \star}$ & $-0.0324^{\star \star \star}$ & $-0.0396^{\star \star \star}$ & $0.0802^{\star \star *}$ \\
\hline & $(0.0024)$ & $(0.0012)$ & $(0.0012)$ & $(0.0016)$ \\
\hline \multirow[t]{2}{*}{ West North Central } & $-0.0227^{\star \star \star}$ & $-0.0412^{\star \star \star}$ & $-0.0463^{\star \star \star}$ & $0.1102^{\star * \star}$ \\
\hline & $(0.0026)$ & $(0.0016)$ & $(0.0015)$ & $(0.0019)$ \\
\hline \multirow[t]{2}{*}{ South Atlantic } & $0.1436^{\star \star \star}$ & $-0.0202^{\star \star \star}$ & $-0.0449^{\star \star \star}$ & $-0.0785^{\star \star \star}$ \\
\hline & $(0.0024)$ & $(0.0009)$ & $(0.0011)$ & $(0.0015)$ \\
\hline \multirow[t]{2}{*}{ East South Central } & $0.0182^{\star \star \star}$ & $-0.0424^{\star \star \star}$ & $-0.0416^{\star \star \star}$ & $0.0658^{\star \star \star}$ \\
\hline & $(0.0035)$ & $(0.0017)$ & $(0.0017)$ & $(0.0023)$ \\
\hline \multirow[t]{2}{*}{ West South Central } & $0.0266^{\star \star \star}$ & $-0.0283^{\star \star \star}$ & $-0.0185^{\star \star \star}$ & $0.0202^{\star \star \star}$ \\
\hline & $(0.0031)$ & $(0.0013)$ & $(0.0011)$ & $(0.0018)$ \\
\hline \multirow[t]{2}{*}{ Mountain } & $0.0289 * * *$ & $-0.0319^{\star \star \star}$ & $-0.0179^{* \star *}$ & $0.0209^{* * *}$ \\
\hline & $(0.0034)$ & $(0.0014)$ & $(0.0012)$ & $(0.0020)$ \\
\hline Parameters & Omega-3 & Organic & Cage-free & Conventional \\
\hline
\end{tabular}


Table 3. (Continued)

\begin{tabular}{|c|c|c|c|c|}
\hline Parameters & Omega-3 & Organic & Cage-free & Conventional \\
\hline \multicolumn{5}{|l|}{ Demographic variables } \\
\hline \multirow[t]{2}{*}{ Household size } & $-0.0067^{\star \star \star}$ & $0.0073^{\star \star \star}$ & $-0.0059^{\star \star \star}$ & $0.0199^{\star \star \star}$ \\
\hline & $(0.0007)$ & $(0.0005)$ & $(0.0005)$ & $(0.0006)$ \\
\hline \multirow[t]{2}{*}{ Race: White } & $-0.0046^{\star \star}$ & $-0.0081^{\star \star \star}$ & $-0.0055^{\star \star \star}$ & $0.0182^{\star \star *}$ \\
\hline & $(0.0021)$ & $(0.0011)$ & $(0.0011)$ & (0.0014) \\
\hline \multirow[t]{2}{*}{ Race: Black } & $-0.0083^{\star \star \star}$ & $-0.0099^{\star \star \star}$ & $-0.0162^{\star \star \star}$ & $0.0344^{\star \star \star}$ \\
\hline & $(0.0025)$ & $(0.0015)$ & $(0.0015)$ & $(0.0018)$ \\
\hline \multirow[t]{2}{*}{ Race: Asian } & -0.0016 & $0.0163^{\star \star \star}$ & -0.0018 & $-0.0128^{\star \star \star}$ \\
\hline & $(0.0032)$ & $(0.0012)$ & $(0.0014)$ & $(0.0019)$ \\
\hline \multirow[t]{2}{*}{ Age: under 25 years } & $-0.0316^{\star \star \star}$ & $0.0097^{\star \star \star}$ & $0.0164^{\star \star \star}$ & 0.0055 \\
\hline & $(0.0064)$ & $(0.0037)$ & (0.0039) & $(0.0047)$ \\
\hline \multirow[t]{2}{*}{ Age: $25-44$ years } & $-0.0244^{\star \star \star}$ & $0.0166^{\star \star \star}$ & $0.0213^{\star \star \star}$ & $-0.0135^{\star \star \star}$ \\
\hline & $(0.0016)$ & $(0.0010)$ & $(0.0011)$ & $(0.0012)$ \\
\hline \multirow[t]{2}{*}{ Age: $45-64$ years } & $-0.0217^{\star \star \star *}$ & $0.0044^{\star \star \star}$ & $0.0063^{\star \star \star}$ & $0.0110^{\star \star \star}$ \\
\hline & $(0.0012)$ & $(0.0009)$ & $(0.0008)$ & $(0.0010)$ \\
\hline \multirow[t]{2}{*}{ Employment: under 35 hours } & 0.0004 & $0.0060^{\star \star \star}$ & $0.0106^{\star \star \star}$ & $-0.0170^{\star \star \star}$ \\
\hline & $(0.0012)$ & $(0.0008)$ & $(0.0008)$ & $(0.0010)$ \\
\hline \multirow[t]{2}{*}{ Employment: 35 hours and above } & $0.0055^{\star \star \star}$ & $0.0029 * \star \star$ & $0.0064^{\star \star \star}$ & $-0.0148^{\star \star \star}$ \\
\hline & $(0.0011)$ & $(0.0007)$ & $(0.0007)$ & $(0.0008)$ \\
\hline \multirow[t]{2}{*}{ Education: less than high school } & $-0.0483^{\star \star \star *}$ & $-0.0274^{\star \star \star}$ & $-0.0304^{\star \star \star}$ & $0.1060^{\star \star *}$ \\
\hline & $(0.0031)$ & $(0.0024)$ & $(0.0021)$ & $(0.0025)$ \\
\hline \multirow[t]{2}{*}{ Education: high school only } & $-0.0324^{\star \star \star}$ & $-0.0329^{\star \star \star}$ & $-0.0299^{\star \star \star}$ & $0.0953^{\star \star \star}$ \\
\hline & $(0.0013)$ & $(0.0010)$ & $(0.0009)$ & $(0.0011)$ \\
\hline \multirow[t]{2}{*}{ Education: some college degree only } & $-0.0165^{\star \star \star}$ & $-0.0204^{\star \star \star}$ & $-0.0164^{\star \star \star}$ & $0.0533^{\star \star \star}$ \\
\hline & $(0.0011)$ & $(0.0008)$ & $(0.0008)$ & $(0.0009)$ \\
\hline \multirow[t]{2}{*}{ Marital status: married } & $0.0173^{\star \star \star}$ & $0.0014^{\star \star}$ & $0.0072^{\star \star \star}$ & $-0.0259^{\star \star \star}$ \\
\hline & $(0.0011)$ & $(0.0007)$ & $(0.0007)$ & $(0.0009)$ \\
\hline \multirow[t]{2}{*}{ Presence of children: At least one child } & $0.0039^{\star \star}$ & $0.0057^{\star \star \star}$ & 0.0013 & $-0.0109^{\star \star \star}$ \\
\hline & $(0.0016)$ & $(0.0010)$ & $(0.0010)$ & $(0.0012)$ \\
\hline \multicolumn{5}{|l|}{ Time fixed effects } \\
\hline \multirow[t]{2}{*}{ Year 2014} & $0.0658^{\star \star \star}$ & $-0.0378^{\star \star \star}$ & $-0.0495^{\star \star \star}$ & $0.0214^{\star \star \star}$ \\
\hline & $(0.0013)$ & $(0.0010)$ & $(0.0010)$ & $(0.0011)$ \\
\hline \multirow[t]{2}{*}{ Year 2015} & $0.0102^{\star \star \star}$ & $-0.0105^{\star \star *}$ & $-0.0292^{\star \star \star}$ & $0.0296^{\star \star \star}$ \\
\hline & $(0.0012)$ & $(0.0008)$ & $(0.0009)$ & $(0.0009)$ \\
\hline
\end{tabular}

Notes: Values in parentheses are the standard errors. Single, double, and triple asterisks $\left({ }^{*},{ }^{\star \star},{ }^{\star \star \star}\right)$ indicate [statistical] significance at the $10 \%, 5 \%$, and $1 \%$ level, respectively. Researcher(s) own analyses calculated (or derived) based in part on data from The Nielsen Company (US), LLC and marketing databases provided through the Nielsen Datasets at the Kilts Center for Marketing Data Center at The University of Chicago Booth School of Business. 
Table 4. Parameter estimates and standard errors from the price and expenditure reduced-form equations

\begin{tabular}{|c|c|c|c|c|c|}
\hline Equation & \multicolumn{4}{|c|}{ Reduced-form price equations $\left[\log \left(p_{h j t}\right)\right]$} & \multirow{2}{*}{$\begin{array}{c}\begin{array}{c}\text { Reduced-form income } \\
\text { equation }\left[\log \left(X_{h t}\right)\right]\end{array} \\
\text { Egg } \\
\text { expenditures }\end{array}$} \\
\hline Parameter & Omega-3 & Organic & Cage-free & Conventional & \\
\hline \multirow[t]{2}{*}{ Intercept } & $-0.3295^{\star \star \star}$ & $-0.1302^{\star \star \star}$ & $0.4059^{\star \star *}$ & $-1.2998^{\star * *}$ & $0.1081^{\star \star \star}$ \\
\hline & $(0.0084)$ & $(0.0065)$ & $(0.0061)$ & (0.0309) & $(0.0076)$ \\
\hline \multicolumn{6}{|l|}{ Region fixed effects } \\
\hline \multirow[t]{2}{*}{ New England } & $0.0252^{\star \star \star}$ & $0.2269^{\star \star \star}$ & $-0.2050^{\star \star \star}$ & $-0.0177^{\star \star \star}$ & $-0.0553^{\star \star \star}$ \\
\hline & (0.0119) & $(0.0103)$ & $(0.0100)$ & $(0.0007)$ & $(0.0130)$ \\
\hline \multirow[t]{2}{*}{ Middle Atlantic } & $-0.4503^{\star \star \star}$ & $-0.3891^{\star \star \star}$ & $-0.5545^{\star \star \star}$ & $-0.1803^{\star \star \star}$ & -0.0108 \\
\hline & $(0.0090)$ & $(0.0079)$ & $(0.0078)$ & $(0.0077)$ & (0.0096) \\
\hline \multirow[t]{2}{*}{ East North Central } & $-0.3797^{\star \star \star}$ & $-0.3442^{\star \star *}$ & $-0.6720^{\star \star *}$ & $-0.5243^{\star \star \star *}$ & $-0.2066^{\star * *}$ \\
\hline & $(0.0084)$ & $(0.0074)$ & $(0.0072)$ & $(0.0071)$ & $(0.0091)$ \\
\hline \multirow[t]{2}{*}{ West North Central } & $-0.3355^{\star \star \star}$ & $-0.2385^{\star \star \star}$ & $-0.5473^{\star \star \star}$ & $-0.4379^{\star \star \star}$ & $-0.2209^{\star \star \star}$ \\
\hline & $(0.0105)$ & $(0.0092)$ & $(0.0087)$ & $(0.0092)$ & $(0.0110)$ \\
\hline \multirow[t]{2}{*}{ South Atlantic } & -0.0031 & $-0.0218^{\star \star \star}$ & $-0.2238^{\star \star \star}$ & $-0.2086^{\star \star \star}$ & $-0.0462^{\star \star \star}$ \\
\hline & (0.0079) & $(0.0071)$ & $(0.0069)$ & $(0.0067)$ & $(0.0087)$ \\
\hline \multirow[t]{2}{*}{ Eats South Central } & $-0.4369^{\star \star \star}$ & $-0.1881^{\star \star \star}$ & $-0.6419^{\star \star \star}$ & $-0.3512^{\star \star \star}$ & $-0.0825^{\star \star *}$ \\
\hline & $(0.0111)$ & $(0.0100)$ & $(0.0096)$ & (0.0099) & $(0.0121)$ \\
\hline \multirow[t]{2}{*}{ West South Central } & $-0.4387^{\star \star \star}$ & $-0.0650^{\star \star \star}$ & $-0.455^{\star \star \star} 1$ & $-0.2680^{\star \star \star}$ & $-0.0597^{\star \star \star}$ \\
\hline & $(0.0091)$ & $(0.0083)$ & $(0.0080)$ & $(0.0079)$ & $(0.0101)$ \\
\hline \multirow[t]{2}{*}{ Mountain } & $-0.2616^{\star \star \star}$ & -0.0050 & $-0.0784^{\star \star \star}$ & $-0.2455^{\star \star \star}$ & -0.0101 \\
\hline & $(0.0101)$ & $(0.0091)$ & $(0.0089)$ & $(0.0089)$ & (0.0113) \\
\hline \multicolumn{6}{|l|}{ Time fixed effects } \\
\hline \multirow[t]{2}{*}{ Year 2014} & $1.6203^{\star \star \star}$ & $0.3494^{\star \star \star}$ & $-1.3006^{\star \star \star}$ & $2.2580^{\star \star \star}$ & $-0.4691^{\star \star \star}$ \\
\hline & $(0.0108)$ & $(0.0052)$ & $(0.0068)$ & $(0.0470)$ & $(0.0061)$ \\
\hline \multirow[t]{2}{*}{ Year 2015} & $0.4997^{\star \star \star}$ & $0.5502^{\star \star \star}$ & $0.9253^{\star \star \star}$ & $2.5567^{\star \star \star}$ & $0.2397^{\star \star \star}$ \\
\hline & $(0.0054)$ & $(0.0048)$ & $(0.0053)$ & $(0.0477)$ & $(0.0056)$ \\
\hline \multirow[t]{2}{*}{ Price instrument } & $-0.6714^{\star \star \star}$ & $-0.6238^{\star \star \star}$ & $-0.9576^{\star \star \star}$ & $-0.8115^{\star \star \star}$ & - \\
\hline & $(0.0044)$ & $(0.0023)$ & $(0.0037)$ & $(0.0230)$ & - \\
\hline \multirow[t]{2}{*}{ Household income } & - & - & - & - & $0.0623^{\star * \star}$ \\
\hline & - & - & - & - & $(0.0024)$ \\
\hline
\end{tabular}

Notes: Values in parentheses are the standard errors. Single, double, and triple asterisks $\left({ }^{*},{ }^{* *},{ }^{* * *}\right)$ indicate [statistical] significance at the $10 \%, 5 \%$, and $1 \%$ level, respectively. Researcher(s) own analyses calculated (or derived) based in part on data from The Nielsen Company (US), LLC and marketing databases provided through the Nielsen Datasets at the Kilts Center for Marketing Data Center at The University of Chicago Booth School of Business.

cage-free eggs vis-a-vis other households. Asian households allocate higher expenditures to organic eggs and less to conventional eggs. With regard to the regional egg consumption patterns, consumers in New England, Middle Atlantic, South Atlantic, Central and Mountain regions of the United States purchase more omega-3 compared to those in the Pacific region. Lastly, conventional eggs are found to be more popular in the central and mountain parts of the country. 
To evaluate the relative importance of the demand determinants, we perform the Shapley decomposition method. Our findings indicate that the economic variables included provide the bulk of the explanatory power with their contribution to the goodness-of-fit being $87.8 \%$, $87.9 \%, 86.4 \%$, and $86.2 \%$ for omega-3, organic, cage-free, and conventional eggs, respectively. Demographic variables, on the other hand, collectively account for $3.7 \%, 6.5 \%, 6.1 \%$, and $3.8 \%$ of the overall explanatory power of the model for the respective egg types. Finally, the regional and time fixed effects are responsible for the remaining $8.5 \%, 5.6 \%, 7.6 \%$, and $10.0 \%$ of the goodness-of-fit for the four egg products considered in this study.

As can be seen from Table 4, almost all parameter estimates from the reduced-form price and expenditure equations are statistically significant at standard levels of significance. Further, the results from a first stage $F$-test indicate that our instruments meet the relevance criterion. Specifically, the $F$-statistic value for the reduced-form price equations ranges from 2,248 for the omega-3 to 7,546 for conventional eggs, and the $F$-statistic for the expenditure reduced-form equation was estimated to be 1,360 (all corresponding $P$-values $<0$ ). Importantly, the income coefficient in the expenditure equation is estimated to be 0.0623 , which indicates that only $6.2 \%$ of an income rise is allocated to egg expenditures.

Table 5 presents uncompensated price, expenditure, and income elasticities of demand evaluated at the sample mean values. All own-price elasticities are statistically significant and have the expected negative sign, conforming to the law of demand. Specifically, demand is price-elastic for organic (-1.0067) and cage-free eggs $(-1.0018)$, and inelastic for omega-3 $(-0.9270)$ and conventional (-0.2348) eggs, which is in accord with prior studies such as Heng (2015) and Lusk (2010) that used similar product definitions. In contrast, Blaylock and Burbee (1985) estimate the ownprice elasticity of demand to be -0.1429 , which is driven by the aggregate nature of the product definition. Other similar studies also report own-price elasticities of demand for eggs falling between -0.08 and -0.27 (Andreyeva, Long, and Brownell, 2010; Kastens and Brester, 1996; Okrent and Alston, 2011). These findings suggest that a price reduction is a revenue-enhancing move for organic and cage-free egg manufacturers in the short-run; however, a price increase is recommended for omega-3 and conventional egg manufacturers.

To empirically evaluate the statistical difference of our own-price elasticities from 0 and -1 , we conduct a Krinsky-Robb test in the spirit of Tonsor and Marsh (2007) and Hovhannisyan et al. (2019) (also see Krinsky and Robb, 1986). Specifically, we employ a bootstrapping procedure to generate 1,000 own-price elasticity estimates for the four egg types using the parameter and variance estimates from our empirical framework and a multivariate normal distribution. The respective $P$-values for these one-sided hypotheses are calculated as the proportion of bootstrapgenerated estimates that differ from 0 and -1 , respectively. The results from this test indicate that own-price elasticities are different from 0 and -1 for all four egg types. ${ }^{13}$

Further, organic (1.1003) and cage-free (1.0145) eggs are found to be expenditure elastic, while omega-3 (0.9880) and conventional (0.9516) are expenditure inelastic, which is similar to the empirical results reported by Lusk (2010). Not surprisingly, while all positive, income elasticity estimates are considerably lower in magnitude as compared to the respective expenditure elasticities, given the small share of household food budget accounted for by egg purchases. Specifically, income elasticities vary from 0.0593 for conventional eggs to 0.0685 for organic eggs. Similar income elasticity estimates for various egg types were obtained by Bakhtavoryan and Lopez (2020).

Table 6 reports the compensated own- and cross-price elasticity estimates and Allen elasticities. All compensated own-price elasticities are negative and significant and are in the range of -1.0045 for organic eggs to -0.1849 for conventional eggs. Additionally, all compensated cross-price elasticities are positive and significant, which is indicative of net substitutability among the egg types

\footnotetext{
${ }^{13}$ The $P$-values associated with the Krinsky-Robb test represent the share of bootstrapped elasticities that are different from -1 .
} 
Table 5. Uncompensated (Marshallian) own-price, cross-price, expenditure, and income elasticities of demand from the EASI system

\begin{tabular}{|c|c|c|c|c|c|c|}
\hline Egg & Omega-3 & Organic & Cage-free & Conventional & Expenditure & Income \\
\hline \multirow[t]{2}{*}{ Omega-3 } & $-0.9270^{\star * *}$ & $0.0304^{\star \star \star}$ & $0.0301^{\star \star \star}$ & $0.8050^{\star \star \star}$ & $0.9880^{\star \star \star}$ & $0.0616^{\star \star \star}$ \\
\hline & $(0.0010)$ & $(0.0006)$ & $(0.0006)$ & $(0.0023)$ & $(0.0031)$ & $(0.0012)$ \\
\hline \multirow[t]{2}{*}{ Organic } & $0.0884^{\star \star \star}$ & $-1.0067^{\star \star \star}$ & $0.0404^{\star \star \star}$ & $0.8093^{\star \star *}$ & $1.1003^{\star \star \star}$ & $0.0685^{* * *}$ \\
\hline & $(0.0007)$ & $(0.0007)$ & $(0.0005)$ & $(0.0023)$ & $(0.0020)$ & $(0.0022)$ \\
\hline \multirow[t]{2}{*}{ Cage-free } & $0.0872^{\star \star \star}$ & $0.0420^{\star \star \star}$ & $-1.0018^{\star \star \star}$ & $0.8093^{\star \star \star}$ & $1.0145^{\star \star \star}$ & $0.0632^{\star \star \star}$ \\
\hline & (0.0008) & $(0.0006)$ & $(0.0008)$ & $(0.0022)$ & $(0.0028)$ & $(0.0010)$ \\
\hline \multirow[t]{2}{*}{ Conventional } & $0.0953^{\star \star *}$ & $0.0417^{\star \star \star}$ & $0.0386^{\star \star \star}$ & $-0.2348^{\star \star \star}$ & $0.9516^{\star \star \star}$ & $0.0593^{\star \star *}$ \\
\hline & $(0.0006)$ & $(0.0003)$ & $(0.0003)$ & $(0.0023)$ & $(0.0020)$ & $(0.0002)$ \\
\hline
\end{tabular}

Notes: Elasticities are calculated at the sample means. Values in the parentheses are the standard errors. Single, double, and triple asterisks $\left({ }^{*},{ }^{* *},{ }^{* \star *}\right)$ indicate [statistical] significance at the $10 \%, 5 \%$, and $1 \%$ level, respectively. Researcher(s) own analyses calculated (or derived) based in part on data from The Nielsen Company (US), LLC and marketing databases provided through the Nielsen Datasets at the Kilts Center for Marketing Data Center at The University of Chicago Booth School of Business.

considered. These results are further confirmed by the Allen elasticities $\left(\sigma_{i j}=\frac{e_{i j}^{H}}{w_{j}}\right)$, which are symmetric and indicate the strength of substitution effects with no regard for direction. These substitutability relationships between the egg types considered are in line with the empirical findings offered by Lusk (2010) and Bakhtavoryan and Lopez (2020).

As a final exercise, we examine the effects of Japanese egg tariff reduction on the US egg prices and consumer welfare. As already explained above, this is carried out in two steps. In the first step, we use equation (13) to calculate proportionate egg price change in the United States brought by Japanese egg tariff reduction. This computation is based on domestic egg demand elasticity estimated in this study $\left(e_{D}\right)$ (i.e., the respective uncompensated own-price elasticities presented in Table 5), own-price elasticity of domestic supply $\left(e_{S}\right)$ of 0.94 borrowed from Schmit and Kaiser (1998) (i.e., the latest estimate available to our knowledge), price elasticity of Japan's egg import demand $\left(e_{M}\right)$ of -1.355 obtained from Sasaki and Yoshida (2017), and data on domestic demand $(D)$, supply (S), and import demand $(M)$ taken from the US Department of Agriculture Economic Research Service (2020) and US Department of Agriculture Foreign Agriculture Service (2020), respectively. In the second step, we use the proportionate change in US egg price to compute consumer welfare change over the period 2020-2023 using equation (11).

Table 7 provides UPEEC-calculated tariff reductions, changes in egg prices caused by the tariff reductions, and CV estimates per unique household and projected for the entire United States. Specifically, UPEEC predicts tariff reductions for eggs to be $14.2 \%, 10.7 \%, 7.1 \%$, and $3.6 \%$, for years 2020 through 2023, respectively (UPEEC, 2019), which reflects a gradual tariff phaseout. These tariff reductions cause an increase in the Japanese demand for the US-supplied eggs, which results in egg price increases in the United States (see equation [13]). Using these price changes, we find that household-specific CV estimates vary from $\$ 0.4106$ to $\$ 0.0993$ over 2020-2023. These findings indicate that a typical household is expected to experience a $\$ 0.4106$ welfare loss in 2020 as a result of tariff-induced egg price increase, which translates into a $\$ 52.8$ million welfare loss on a national scale (U.S. Census Bureau, 2020). Similarly, the CV is projected to be $\$ 38.2$ million in 2021, $\$ 24.4$ million in 2022, and $\$ 12.8$ million in 2023 for the entire United States. Thus, Japan's reduction of tariffs on the egg imports from the US and the resulting higher egg prices in the United States adversely affect domestic egg consumers. ${ }^{14}$

\footnotetext{
${ }^{14}$ Variation in elasticity estimates showed results were not sensitive.
} 
Table 6. Compensated (Hicksian) own-price and cross-price elasticities of demand from the EASI system

\begin{tabular}{|c|c|c|c|c|}
\hline \multicolumn{5}{|c|}{ Hicksian Elasticity } \\
\hline Egg & Omega 3 & Organic & Cage-free & Conventional \\
\hline \multirow[t]{2}{*}{ Omega 3} & $-0.9213^{\star \star \star}$ & $0.0323^{\star \star \star}$ & $0.0321^{\star \star \star}$ & $0.8568^{\star \star \star}$ \\
\hline & $(0.0010)$ & $(0.0006)$ & $(0.0006)$ & $(0.0011)$ \\
\hline \multirow[t]{2}{*}{ Organic } & $0.0948^{\star \star *}$ & $-1.0045^{\star \star \star}$ & $0.0426^{\star \star \star}$ & $0.8671^{\star \star *}$ \\
\hline & $(0.0006)$ & $(0.0007)$ & $(0.0005)$ & $(0.0007)$ \\
\hline \multirow[t]{2}{*}{ Cage-free } & $0.0932^{\star \star \star}$ & $0.0440^{\star \star \star}$ & $-0.9997^{\star \star \star}$ & $0.8626^{\star \star \star}$ \\
\hline & (0.0008) & $(0.0006)$ & $(0.0008)$ & $(0.0009)$ \\
\hline \multirow[t]{2}{*}{ Conventional } & $0.1008^{\star \star \star}$ & $0.0435^{\star \star \star}$ & $0.0406^{\star \star \star}$ & $-0.1849^{\star \star \star}$ \\
\hline & $(0.0005)$ & $(0.0003)$ & $(0.0003)$ & $(0.0244)$ \\
\hline \multicolumn{5}{|c|}{ Allen Elasticity } \\
\hline Egg & Omega 3 & Organic & Cage-free & Conventional \\
\hline \multirow[t]{2}{*}{ Omega 3} & $-9.8085^{\star \star \star}$ & & & \\
\hline & $(0.0104)$ & & & \\
\hline \multirow[t]{2}{*}{ Organic } & $1.0301^{\star \star \star}$ & $-32.0244^{\star \star \star}$ & & \\
\hline & $(0.0203)$ & $(0.0208)$ & & \\
\hline \multirow[t]{2}{*}{ Cage-free } & $0.9810^{\star \star \star}$ & $1.0177^{\star \star \star}$ & $-30.5195^{\star \star \star}$ & \\
\hline & $(0.0188)$ & $(0.0013)$ & $(0.0256)$ & \\
\hline \multirow[t]{2}{*}{ Conventional } & $1.3015^{\star \star \star}$ & $1.0298^{\star \star \star}$ & $1.0245^{\star \star \star}$ & $-0.2196^{\star \star *}$ \\
\hline & $(0.0148)$ & $(0.0008)$ & $(0.0010)$ & $(0.0051)$ \\
\hline
\end{tabular}

Notes: Elasticities are calculated at the sample means. Values in parentheses are the standard errors. Single, double, and triple asterisks ( ${ }^{*}$, ${ }^{*}$, $\left.{ }^{\star \star \star}\right)$ indicate [statistical] significance at the $10 \%, 5 \%$, and $1 \%$ level, respectively. Researcher(s) own analyses calculated (or derived) based in part on data from The Nielsen Company (US), LLC and marketing databases provided through the Nielsen Datasets at the Kilts Center for Marketing Data Center at The University of Chicago Booth School of Business.

Based on the magnitude of the impact, however, the unfavorable consequences for the US consumers appear to be relatively less alarming.

\section{Concluding Remarks}

We utilize a flexible demand framework, namely an Exact Affine Stone Index (EASI) model, to estimate demand for omega-3, organic, cage-free, and conventional eggs in the United States. Our empirical framework recognizes demand inter-relationships among the egg types, allows for flexible Engel curves and unobserved consumer heterogeneity, as well as addresses price and expenditure endogeneity via a Full Information Maximum Likelihood framework. We further address the econometric issue of left-censoring resulting from the disaggregate nature of our householdlevel survey data. Our study also offers a broader egg product and geographical coverage in comparison to the previous literature, thus, giving the promise of generating a fuller characterization of the egg demand structure in the United States. Finally, to illustrate the policy relevance of our findings, we quantify the adverse consumer welfare consequences of rising egg prices in the US brought by Japan's egg tariff reductions.

The results emerging from this study indicate that demand for organic and cage-free eggs is price-elastic, while that for the omega- 3 and conventional eggs is price-inelastic; information that egg manufacturers can utilize in designing their pricing strategies to raise total revenue in the 
Table 7. Tariff reductions, percentage changes in egg prices, and compensating variations by year

\begin{tabular}{|c|c|c|c|c|c|c|c|c|}
\hline \multirow[b]{3}{*}{ Tariff reductions } & \multicolumn{4}{|c|}{2020} & \multicolumn{4}{|c|}{2021} \\
\hline & \multicolumn{4}{|c|}{0.1420} & \multicolumn{4}{|c|}{0.1070} \\
\hline & Omega-3 & Organic & Cage-free & Conventional & Omega 3 & Organic & Cage-free & Conventional \\
\hline Changes in the prices (\%) & 0.1006 & 0.1007 & 0.1007 & 0.1007 & 0.0729 & 0.0729 & 0.0729 & 0.0729 \\
\hline Compensating variation per household, \$ & & 0.4106 & & & & 0.2972 & & \\
\hline \multirow[t]{3}{*}{ Compensating variation projected for the entire US, million $\$$} & & 52.7949 & & & & 38.2140 & & \\
\hline & \multicolumn{4}{|c|}{2022} & \multicolumn{4}{|c|}{2023} \\
\hline & \multicolumn{4}{|c|}{0.0710} & \multicolumn{4}{|c|}{0.0360} \\
\hline Tariff reductions & Omega-3 & Organic & Cage-free & Conventional & Omega 3 & Organic & Cage-free & Conventional \\
\hline Changes in the prices (\%) & 0.0465 & 0.0465 & 0.0465 & 0.0465 & 0.0227 & 0.0227 & 0.0227 & 0.0227 \\
\hline Compensating variation per household, \$ & & 0.1896 & & & & 0.0993 & & \\
\hline Compensating variation projected for the entire US, million $\$$ & & 24.3788 & & & & 12.7629 & & \\
\hline
\end{tabular}

Notes: Uncompensated own-price elasticities from this study are used in the calculations of CV. Own-price elasticity of supply used is 0.94 (Schmit and Kaiser, 1998), and price elasticity of Japan's egg import demand of -1.355 is borrowed from Sasaki and Yoshida (2017). Researcher(s) own analyses calculated (or derived) based in part on data from The Nielsen Company (US), LLC and marketing databases provided through the Nielsen Datasets at the Kilts Center for Marketing Data Center at The University of Chicago Booth School of Business. 
short-run. ${ }^{15}$ In addition, a significant substitutability relationship is established between the egg types considered, as evidenced by the sign of the respective compensated cross-price elasticities. This information may prove useful to egg producers in making decisions regarding input procurement and inventory management. Based on the income elasticity estimates, we further find that all the eggs considered are necessity goods. A variety of household economic and demographic characteristics included in the study are estimated to be important determinants of egg consumption, which can be used by egg manufacturers in redesigning marketing strategies to better address the needs of different demographic markets and expand their current customer base. Finally, we find that US households experienced a measurable welfare loss on a national scale following the reduction of Japanese tariffs on the US-exported eggs. The overall effect on the US economy could be even bigger, given our narrow focus on eggs for final consumption that ignore the effect on other products that use eggs as an input. Our results may prove useful in designing adequate and effective policies on the part of the US government for mitigating the adverse effects of rising egg prices in the country. ${ }^{16}$

Future research would significantly benefit from the use of detailed wholesale and retail-level cost data to analyze a simultaneous system of supply and demand. This would account not only for true simultaneity between supply and demand but would also allow obtaining supply elasticities to be used in welfare analysis. Finally, given that unconditional elasticities are more relevant for making policy decisions, our estimation of conditional elasticities is a limitation of this study. Future studies would benefit significantly by estimating unconditional elasticities, whenever possible.

Data Availability Statement. Data subject to third-party restrictions: The data that support the findings of this study are available from Nielsen. Restrictions apply to the availability of these data, which were used under license for this study. Data are available from Rafael Bakhtavoryan with the permission of Nielsen and USDA.

Funding Statement. This work was supported by Wyoming Agricultural Experiment Station funding provided through the USDA National Institute of Food and Agriculture, Hatch project 1016328.

Conflict of Interest. None.

\section{References}

American Egg Board. Specialty Eggs. Internet site: https://www.aeb.org/images/website/documents/foodservice-professionals/ specialty-eggs/specialty-eggs-1005.pdf (Accessed November 13, 2019).

Andreyeva, T., M.W. Long, and K.D. Brownell. "The Impact of Food Prices on Consumption: A Systematic Review of Research on the Price Elasticity of Demand for Food." American Journal of Public Health 100(2010):216-22.

Arnade, C., D. Pick, and M. Gehlhar. "Testing and Incorporating Seasonal Structures into Demand Models for Fruit." Agricultural Economics 33(2005):527-32.

Asselin, A. M. "Eggcentric Behavior: Consumer Characteristics that Demonstrate Greater Willingness to Pay for Functionality." American Journal of Agricultural Economics 5(2005):1339-44.

Bakhtavoryan, R., and J. Lopez. "Empirical Analysis of Factors Influencing Households' Demand for Omega-3 Enriched Eggs in the United States." Paper presented at the annual meeting of the Southern Agricultural Economics Association, Louisville, KY, February, 1-4, 2020.

Blaylock, J., and C. Burbee. "Consumer Demand for Eggs and Market Implications." US Department of Agriculture, Economic Research Service, National Economics Division, Washington, D.C. 20005-4788, Report No. AGES850924 (November 1985).

Chang, J.B., J.L. Lusk, and F.B. Norwood. “The Price of Happy Hens: A Hedonic Analysis of Retail Egg Prices.” Journal of Agricultural and Resource Economics 35(2010):406-23.

\footnotetext{
${ }^{15}$ These results are only consistent with the data used in this study. While providing a crucial piece of information about tariff effects and price elasticities, our results should not be interpreted as the final conclusion.

${ }^{16}$ Given the number of challenges that the Nielsen Homescan data present, we highly encourage other researchers to use data from other sources either in combination with Nielsen or separately, to ensure more robust learning and improved outcome prediction.
} 
Chase, D., J.P. Emunu, T. Nilsson, D. McCann-Hiltz, and Y. Peng. “Canadian Consumers' Purchasing Behavior of Omega-3 Products." Journal of Food Distribution Research 2(2009):12-25.

Deaton, A. "Quality, Quantity, and Spatial Variation of Price." The American Economic Review 78(1988):418-30.

Deaton, A., and J. Muellbauer. "An Almost Ideal Demand System." American Economic Review 70(1980):312-26.

Devadoss, S., and E. Sabala. "Effects of Yuan-Dollar Exchange Rate Changes on World Cotton Markets." Journal of Agricultural and Applied Economics 52(2020):420-39.

Dhar, T., J-P. Chavas, and W. B. Gould. "An Empirical Assessment of Endogeneity Issues in Demand Analysis for Differentiated Products." American Journal of Agricultural Economics 85(2003):605-17.

Dong, D., J.S. Shonkwiler, and O. Capps, Jr. "Estimation of Demand Functions Using Cross-Sectional Household Data: The Problem Revisited." American Journal of Agricultural Economics 80(1998):466-73.

Einav, L., E. Leibtag, and A. Nevo. "On the Accuracy of Nielsen Homescan Data." ERR-69, U.S. Dept. of Agriculture, Econ. Res. Serv. December 2008.

Executive Office of the President of the U.S., Office of the United States Trade Representative. Fact sheet on agriculturerelated provisions of the U.S.-Japan trade agreement. Internet site: https://ustr.gov/about-us/policy-offices/press-office/ factsheets/2019/october/agriculture\%E2\%80\%90related-provisions-of-us-japan-tradeagreement\# (Accessed November 20, 2019).

Grand View Research. "Omega 3 Market Size, Share and Trends Analysis Report by Application, by Region, and Segmented Forecasts, 2019, 2025. https://www.grandviewresearch.com/industry-analysis/omega-3-market (Accessed April 7, 2020).

Green, R., and J.M. Alston. "Elasticities in AIDS Models." American Journal of Agricultural Economics 72(1990):442-45.

GRO Intelligence. 2019. The big egg challenge: Meeting demand for cage free. Internet site: https:/gro-intelligence.com/ insights/articles/the-big-egg-challenge-meeting-demand-for-cage-free (Accessed April 14, 2019).

Guta, D.D. "Application of an Almost Ideal Demand System (AIDS) to Ethiopian Rural Residential Energy Use: Panel Data Evidence.” Energy Policy 50(2012):528-39.

Hausman, J. "Exact Consumer's Surplus and Deadweight Loss." The American Economic Review 71(1981):662-76.

Hausman, J., G. Leonard, and J.D. Zona. "Competitive Analysis with Differentiated Products." Annales d'Economie et de Statistique (1994):159-80.

Heckman, J.J. "The Common Structure of Statistical Models of Truncation, Sample Selection and Limited Dependent Variables and a Simple Estimator for such Models." Annals of Economic and Social Measurement 5(1976):475-92.

Heng, Y. "Three Essays on Differentiated Products and Heterogeneous Consumer Preferences: The Case of Table Eggs." Ph.D. dissertation, Kansas State University, 2015.

Hovhannisyan, V., and M. Bozic. "Price Endogeneity and Food Demand in Urban China." Journal of Agricultural Economics 68(2017):386-406.

Hovhannisyan, V. and S. Devadoss. "Effects of Urbanization on Food Demand in China." Empirical Economics 58(2020):699-721.

Hovhannisyan, V., M. Kondaridze, C. Bastian, and A. Shanoyan. "Empirical Evidence of Changing Food Demand and Consumer Preferences in Russia." Journal of Agricultural and Applied Economics 52(2020):480-501.

Hovhannisyan, V., S. Mendis, and C. Bastian. "An Econometric Analysis of Demand for Food Quantity and Quality in Urban China.” Agricultural Economics 50(2019):3-13.

Hovhannisyan, V., and A. Shanoyan. "An Empirical Analysis of the Welfare Consequences of Rising Food Prices in Urban China: The EASI Approach.” Applied Economic Perspectives and Policy 42(2020):796-814.

Huang, K.S., and B.-H. Lin. "Estimation of Food Demand and Nutrient Elasticities from Household Survey Data." Technical Bulletin 1887. Washington, DC: USDA, Economic Research Service (2000).

Kastens, T.L., and G.W. Brester. "Model Selection and Forecasting Ability of Theory-Constrained Food Demand Systems." American Journal of Agricultural Economics 78(1996):301-12.

Krinsky, I., and A.L. Robb. "On Approximating the Statistical Properties of Elasticities." The Review of Economics and Statistics 68(1986):715-719.

Lewbel, A., and K. Pendakur. “EASI Made Easier." American Economic Review 99(2009): 827-63.

Lusk, J.L. "The Effect of Proposition 2 on the Demand for Eggs in California." Journal of Agricultural and Food Industrial Organization 8(2010):1-20.

Miller, M. and A. Alberini. "Sensitivity of Price Elasticity of Demand to Aggregation, Unobserved Heterogeneity, Price Trends, and Price Endogeneity: Evidence from US Data.” Energy Policy 97(2016):235-49.

Molfino, A., Gioia, G., Fanelli, F.R. and M. Muscaritoli. "The Role for Dietary Omega-3 Fatty Acids Supplementation in Older Adults." Nutrients 6(2014):4058-72.

Okrent, A.M., and J.M. Alston. "Demand for Food in the United States: A Review of Literature, Evaluation of Previous Estimates, and Presentation of New Estimates of Demand." Giannini Foundation Monograph 48, Giannini Foundation of Agricultural Economics, Berkeley, CA (2011).

Pendakur, K. "EASI Made Easier." Quantifying Consumer Preferences. D.J. Slottje, ed. Bingley: Emerald Group Publishing Limited.

Pollak, R.A., and T.J. Wales. "Demographic Variables in Demand Analysis.” Econometrica 49(1981):1533-51. 
Sasaki, Y., and Y. Yoshida. "Factor Decomposition of Japan's Trade Balance." The Research Institute of Economy, Trade and Industry, Discussion Paper Series, 17-E-042(2017):1-47.

Schmit, T.M., and H.M. Kaiser. "Egg Advertising, Dietary Cholesterol Concerns, and U.S. Consumer Demand." Agricultural and Resource Economics Review 27(1998):43-52.

Shiratori, S. "Impact of Nutrition Information on Consumers' Food Purchases." Ph.D. dissertation, University of Minnesota, 2011.

Shonkwiler, J.S., and S.T. Yen. “Two-Step Estimation of a Censored System of Equations.” American Journal of Agricultural Economics 81(1999):972-982.

Statista Research Department. “Most Used Types of Eggs in the U.S. 2011-2019.” Internet site: https://www-statista-com. proxy.tamuc.edu/statistics/282893/us-households-most-used-types-of-eggs-trend/ (Accessed April 13, 2020).

The American Egg Board. Annual Report. Internet site: https://www.aeb.org/images/PDFs/AboutAEB/AEB_Annual_ Report_2018.pdf (Accessed April 15, 2020).

Tonsor, G.T. and T.L. Marsh. "Comparing Heterogeneous Consumption in US and Japanese Meat and Fish Demand." Agricultural Economics 37(2007):81-91.

United Egg Producers. "Housing Environments of U.S. Laying Hens.” Internet site: https://unitedegg.com/facts-stats/ (Accessed April 20, 2020).

United States Trade Representative. Fact Sheet on Agriculture-Related Provisions of the U.S.-Japan Trade Agreement. Internet site: https://ustr.gov/about-us/policy-offices/press-office/factsheets/2019/october/agriculture\%E2\%80\%90relatedprovisions-of-us-japan-trade-agreement (Accessed April 10, 2020).

USA Poultry and Egg Export Council. U.S.-Japan Trade Agreement Now Official. Internet site: https://www.usapeec.org/ newsroom/news/eggproductworkshop/ (Accessed November 9, 2019).

U.S. Census Bureau. "Current Population Survey, March and Annual Social and Economic Supplements." Washington, DC: U.S. Department of Commerce, 2020. Internet site: https://www.census.gov/data/tables/time-series/demo/families/ households.html (Accessed October 8, 2020).

U.S. Census Bureau. American Community Survey, 2010 and 2015. Internet site: https://www.census.gov/acs/www/data/ data-tables-and-tools/data-profiles/ (Accessed October 8, 2019).

U.S. Department of Agriculture, Economic Research Service. Chickens, Turkeys, and Eggs: Annual and Cumulative Yearto-Date U.S. Trade. Washington DC: U.S. Department of Agriculture, Economic Research Service. Internet site: https:// www.ers.usda.gov/data-products/livestock-and-meat-international-trade-data/ (Accessed April 10, 2020).

U.S. Department of Agriculture, Economic Research Service. World Agricultural Supply and Demand Estimates. Internet site: https://www.usda.gov/oce/commodity/wasde/wasde0520.pdf (Accessed April 10, 2020).

U.S. Department of Agriculture, Foreign Agricultural Service. Standard Query. Washington, DC: U.S. Department of Agriculture, Foreign Agricultural Service, Global Agricultural Trade System. Internet site: https:/apps.fas.usda.gov/gats/ default.aspx?publish=1 (Accessed April 10, 2020).

Zhen, C., E.A. Finkelstein, J.M. Nonnemaker, S.A. Karns, and J.E. Todd. "Predicting the Effects of Sugar-Sweetened Beverage Taxes on Food and Beverage Demand in a Large Demand System." American Journal of Agricultural Economics 96(2013):1-25. 


\section{Appendix A}

Let $P, S, D$ denote egg price, domestic supply, and demand, respectively, $M$ be Japanese import demand for US-produced eggs, $P^{*}$ be egg price in Japan with $t$ denoting the Japanese import tariff rate. The egg market equilibrium condition is that domestic demand plus import demand equal the US supply, as given by

$$
D(P)+M(P *)=S(P),
$$

where $P *=(1+t) P=\tau P$.

Substituting $P^{*}$ into equation (A.1) leads to

$$
D(P)+M(\tau P)=S(P) .
$$

To analyze the impact of tariff on US egg price, we totally differentiate equation (A.2) and express change in price in terms of elasticity parameters and tariff changes

$$
\frac{d P}{P}=\frac{M^{\prime}(\tau P)}{\left[S^{\prime}(P)-D^{\prime}(P)-\tau M^{\prime}(\tau P)\right]} d \tau .
$$

Equation (A.3) can be expressed in an elasticity form as shown below

which in an elasticity form is

$$
\frac{d P}{P}=\frac{M^{\prime}(\tau P) \frac{P *}{M}}{\left[S^{\prime}(P) \frac{P}{M}-D^{\prime}(P) \frac{P}{M}-M^{\prime}(\tau P) \frac{P *}{M}\right]} \frac{d \tau}{\tau},
$$

$$
\frac{d P}{P}=\frac{e_{M}}{\left[e_{S} \frac{S}{M}-e_{D} \frac{D}{M}-e_{M}\right]} \frac{d \tau}{\tau},
$$

where $e_{S}, e_{D}, e_{M}$ are elasticities of supply, domestic demand, and import demand for US eggs, respectively. The above expression quantifies the effects of tariff on domestic price, which examines the effects of exchange rate changes on prices and trade flows.

\section{Appendix B}

The EASI expenditure elasticity functions for a system comprising only two equations and cubic Engel curves are provided below:

$$
\begin{aligned}
& e_{1}=\frac{1}{w_{1}}\left(\frac{\left[1+\left(\beta_{21}+\beta_{22} l y+\beta_{23} l y^{2}\right) \ln p_{2}\right]\left(\beta_{11}+\beta_{12} l y+\beta_{13} l y^{2}\right)-\left[\left(\beta_{11}+\beta_{12} l y+\beta_{13} l y^{2}\right) \ln p_{2}\right]\left(\beta_{21}+\beta_{22} l y+\beta_{23} l y^{2}\right)}{\left[1+\left(\beta_{11}+\beta_{12} l y+\beta_{13} l y^{2}\right) \ln p_{1}\right]\left[1+\left(\beta_{21}+\beta_{22} l y+\beta_{23} l y^{2}\right) \ln p_{2}\right]-\left[\left(\beta_{11}+\beta_{12} l y+\beta_{13} l y^{2}\right) \ln p_{2}\right]\left[\left(\beta_{21}+\beta_{22} l y+\beta_{23} l y^{2}\right) \ln p_{1}\right]}\right)+1 \\
& e_{2}=\frac{1}{w_{2}}\left(\frac{\left[1+\left(\beta_{11}+\beta_{12} l y+\beta_{13} l y^{2}\right) \ln p_{1}\right]\left(\beta_{21}+\beta_{22} l y+\beta_{23} l y^{2}\right)-\left[\left(\beta_{21}+\beta_{22} l y+\beta_{23} l y^{2}\right) \ln p_{1}\right]\left(\beta_{11}+\beta_{12} l y+\beta_{13} l y^{2}\right)}{\left[1+\left(\beta_{11}+\beta_{12} l y+\beta_{13} l y^{2}\right) \ln p_{1}\right]\left[1+\left(\beta_{21}+\beta_{22} l y+\beta_{23} l y^{2}\right) \ln p_{2}\right]-\left[\left(\beta_{11}+\beta_{12} l y+\beta_{13} l y^{2}\right) \ln p_{2}\right]\left[\left(\beta_{21}+\beta_{22} l y+\beta_{23} l y^{2}\right) \ln p_{1}\right]}\right)+1
\end{aligned}
$$

Cite this article: Bakhtavoryan R, Hovhannisyan V, Devadoss S, and Lopez J (2021). An Empirical Evaluation of Egg Demand in the United States. Journal of Agricultural and Applied Economics 53, 280-300. https://doi.org/10.1017/aae.2021.9 